\title{
Zebrafish Touch-Insensitive Mutants Reveal an Essential Role for the Developmental Regulation of Sodium Current
}

\author{
Angeles B. Ribera ${ }^{1,2}$ and Christiane Nüsslein-Volhard ${ }^{1}$ \\ ${ }^{1}$ Abteilung III/Genetik, Max-Planck-Institut für Entwicklungsbiologie, Tübingen, Germany D-72076, and 2Department of \\ Physiology and Biophysics, University of Colorado Health Sciences Center, Denver, Colorado 80262
}

\begin{abstract}
Developmental changes in neuronal connectivity and membrane properties underlie the stage-specific appearance of embryonic behaviors. The behavioral response of embryonic zebrafish to tactile stimulation first appears at $27 \mathrm{hr}$ postfertilization. Because the touch response requires the activation of mechanosensory Rohon-Beard neurons, we have used whole-cell recordings in semi-intact preparations to characterize Rohon-Beard cell electrical membrane properties in several touch-insensitive mutants and then to correlate the development of excitability in these cells with changes in wildtype behavior. Electrophysiological analysis of mechanosensory neurons of touch-insensitive zebrafish mutants indicates that in three mutant lines that have been examined the sodium current amplitudes are reduced, and action potentials either have diminished overshoots or are not generated. In macho mutants the action potential never overshoots, and the sodium current remains small; alligator and steifftier show similar but
\end{abstract}

weaker effects. The effects are specific to sodium channel function; resting membrane potentials are unaffected, and outward currents of normal amplitude are present. Developmental analysis of sodium current expression in mechanosensory neurons of wild-type embryos indicates that, during the transition from a touch-insensitive to a touch-sensitive embryo, action potentials acquire larger overshoots and briefer durations as both sodium and potassium currents increase in amplitude. However, in macho touch-insensitive mutants, developmental changes in action potential overshoot and sodium current are absent despite the normal regulation of action potential duration and potassium current. Thus, the maturation of a voltagedependent sodium current promotes a behavioral response to touch. A study of these mutants will allow insight into the genes controlling the maturation of the affected sodium current.

Key words: zebrafish; motility mutants; touch response; Rohon-Beard cells; action potentials; sodium currents
During embryonic development, electrical activity regulates several essential neuronal characteristics, including process outgrowth, synapse formation, and neurotransmitter expression (for review, see Spitzer, 1991; Shatz, 1994; Katz and Shatz, 1996). However, the ability of activity to influence changes in neuronal differentiation often is limited to "critical" developmental periods during which the firing properties of embryonic neurons and the output of newly formed circuits are modified developmentally. Consistent with the temporally restricted ability of activity to alter programs of differentiation and the output of emerging circuits, voltage-dependent ion channel genes display stage- and cell-specific expression patterns during embryonic development of the nervous system (Beckh et al., 1989; Beckh, 1990; Drewe et al., 1992).

Identification of the specific role that an individual ion channel gene plays during development is hindered by the overlapping and temporally complex expression of ion channels. A classic approach for the identification of genes that have essential or

\footnotetext{
Received July 8, 1998; revised Aug. 25, 1998; accepted Aug. 28, 1998.

This work was supported by fellowships from the Fulbright Commission, National Institutes of Health Fogarty Center, and the Guggenheim Foundation to A.B.R. We thank C. Müller, T. Nicolson, J. Rauch, P. van Roessel, and the Max-Planck-Institut Werkstatt for help in setting up a patch-clamp recording rig; C.-B. Chien, D. Gilmour, M. Granato, P. Haffter, S. C. F. Neuhauss, T. Nicolson, and J. Rohrbough for suggestions and/or providing identified fish pairs; S. Fadul for assistance with figure preparation; and C.-B. Chien, S. C. F. Neuhauss, and N. C. Spitzer for comments on this manuscript.

Correspondence should be addressed to Dr. Angeles B. Ribera, Department of Physiology and Biophysics, Box C-240, University of Colorado Health Sciences Center, 4200 East Ninth Avenue, Denver, CO 80262.

Copyright (ㄷ) 1998 Society for Neuroscience $\quad 0270-6474 / 98 / 189181-11 \$ 05.00 / 0$
}

unique functions during embryonic development is saturation scale mutagenesis, followed by the screening of subsequent generations for defects in a property of interest (Nüsslein-Volhard and Weischaus, 1980). The application of this approach to the study of genes required for proper ion channel expression in the developing vertebrate nervous system would require a vertebrate in which large-scale mutagenesis is feasible as well as a rapid screen, thereby enabling efficient examination of large numbers of embryos from different mutant lines. By assaying an aspect or consequence of ion channel function, the screen would allow for the identification of embryos harboring mutations in genes affecting ion channel expression. Ideally, embryonic neurons also would be amenable to electrophysiological analysis at early stages.

Recently, methods have been developed for large-scale mutagenesis of the vertebrate species Danio rerio (Mullins et al., 1994; Solnica-Krezel et al., 1994), and embryonic mutants have been isolated (Driever et al., 1996; Haffter et al., 1996a). Zebrafish embryonic development occurs completely externally, and hundreds of embryos are generated from a single mating. Further, zebrafish start displaying behaviors as early as $1 \mathrm{~d}$ postfertilization (dpf), and function of the nervous system and muscle thus can be evaluated. Using simple behavioral tests, Granato et al. (1996) isolated close to 200 zebrafish motility mutants. Approximately one-third of these have abnormalities in skeletal muscle, whereas two-thirds are defective in locomotion despite apparently normal development of muscle. This latter group comprises 103 alleles and at least 30 genes.

One group of motility mutants does not respond to touch, although these embryos are motile and can swim (Granato et al., 
1996). The specificity of the behavioral deficit suggests a defect originating in mechanosensitive sensory neurons. A semi-intact preparation was developed that allows for the physiological study of mechanosensitive Rohon-Beard sensory neurons in their native environment. In touch-insensitive mutants these neurons fire abnormal action potentials with little or no overshoots. Consistent with the lack of overshooting impulses, a specific reduction in the amplitude of whole-cell voltage-dependent sodium current $\left(I_{\mathrm{Na}}\right)$ is observed. These results implicate an essential role for a Rohon-Beard $I_{\mathrm{Na}}$ in the establishment and maintenance of the behavioral response to touch.

\section{MATERIALS AND METHODS}

Animals. All lines of mutant zebrafish examined in this study are maintained in the Tübingen Stockcenter (http://www.eb.tuebingen.mpg.de/ Abt.3/Stockcenter/). The original ethylnitrosourea-induced mutations were created in fish of the Tübingen strain (Tü; Haffter et al., 1996a) referred to here as "wild-type Tü" (see, for example, Table 2). The mutant lines first were incrossed for at least two generations to yield homozygous forms and then outcrossed for several generations to various other strains, including TL (Tup Long fin; Haffter et al., 1996b) and WIK (Wild India Kalkutta; Rauch et al., 1997) to avoid problems associated with inbreeding. Importantly, the behavioral phenotypes persisted in the resulting different genetic strain backgrounds.

Embryos were obtained from matings of identified heterozygous carriers. The mutations studied here were recessive, and homozygous embryos were identified on the basis of a behavioral phenotype (Granato et al., 1996). Consequently, it is not yet possible to identify and study homozygous mutants at stages before the development of the affected behavior. Staging was done according to the criteria of external morphology as described by Kimmel et al. (1995). Controls consisted of unaffected sibling embryos that could be either homozygous wild-type $(\sim 1 / 3)$ or heterozygous $(\sim 2 / 3)$ for the mutation. Typically, a subset of embryos in a clutch was sorted at the earliest time of appearance of the phenotype (Granato et al., 1996) (see Results); the identification of an embryo as mutant or control was reconfirmed just before dissection and recording.

Intact preparations of spinal cord/neural tube from zebrafish embryos. Physiological recordings were performed on semi-intact preparations of zebrafish embryos. Embryos were mounted on glass coverslips with the use of HistoAcryl (B. Braun, Melsungen, Germany; at the suggestion of Dr. Jeff Rohrbough, Department of Biological Sciences, University of Utah) in the presence of $0.02 \%$ Tricaine. Once mounted, the embryos were killed either by decapitation or by transection at the level of the hindbrain. The skin and meninges ensheathing the spinal cord were removed with tungsten needles. Tricaine was removed by washing the preparations at least five times over the course of 10-15 min with recording solution. Preparations were viewed with differential interference contrast (DIC)/Nomarski optics on a Zeiss Fixed Stage Axioskop microscope (Oberkochen, Germany) at a magnification of $640 \times$. Within a single preparation, recordings were obtained from as many as 10 different Rohon-Beard cells.

Whole-cell recording. Conventional whole-cell patch-clamp techniques (Hamill et al., 1981) were used in either voltage- or current-clamp mode. An EPC-9 amplifier (HEKA, Lambrecht, Germany) was used in conjunction with the PULSE program (HEKA) for the acquisition of data. Current or membrane voltage was sampled at $100 \mu \mathrm{sec}$; a modified $\mathrm{P} / 4$ protocol was used for leak subtraction for the recording of whole-cell currents. Pipettes were pulled from borosilicate glass and had resistances ranging between 4 and $8 \mathrm{M} \Omega$. The composition of bath and pipette solutions (see below) was based on those used for the study of Xenopus spinal neurons with whole-cell recording techniques (O'Dowd et al., 1988) but was increased slightly with respect to the concentration of either $\mathrm{NaCl}$ or $\mathrm{KCl} / \mathrm{CsCl}$. Muscle contractions were blocked by the addition of $0.5 \mu \mathrm{M} \alpha$-bungarotoxin (Sigma-Aldrich Chemie $\mathrm{GmbH}$, Deisenhofen, Germany) to the bath solution.

Both current-clamp and voltage-clamp recordings from a neuron were considered acceptable when the following criteria were met as assessed during an experiment: (1) input resistances $>1 \mathrm{G} \Omega$, and (2) monoexponential decay of the whole-cell capacitative transient (indicative of appropriate access resistance and space clamp). For most of the cells from which current-clamp data were obtained, recordings also were obtained in voltage-clamp mode (see, for example, Figs. 2, 3). For these data as well as for the recordings of isolated $I_{\mathrm{Na}}$, a time to peak of $\leq 2.5 \mathrm{msec}$ for the largest inward current was an additional criterion. None of these criteria led to the inclusion of less/more data from wild-type versus control or mutant embryos.

For the recording of action potentials in current-clamp mode, the pipette solution consisted of (in $\mathrm{mM}) 135 \mathrm{KCl}, 10 \mathrm{HEPES}$, and 10 EGTA, pH 7.2 with $\mathrm{KOH}$. The bath solution contained (in mM) $145 \mathrm{NaCl}, 3 \mathrm{KCl}$, $10 \mathrm{CaCl}_{2}$, and $10 \mathrm{HEPES}, \mathrm{pH} 7.2$ with $\mathrm{NaOH}$. Resting membrane potential was determined as the membrane voltage measured in current clamp with no applied current. For the recording of action potentials the initial holding potential was kept near $-80 \mathrm{mV}$ by steady-state injection of current. Action potentials were elicited by applying a series of brief $(2-2.5 \mathrm{msec})$ depolarizing current pulses of increasing amplitude, ranging between 100 and $1000 \mathrm{pA}$. Typically, single action potentials were elicited by current injections of $2-2.5$ msec duration. After action potential recordings were obtained, the amplifier was switched to voltageclamp mode, and total whole-cell voltage-dependent currents were recorded by using pipette and bath solutions like those for the measurement of action potentials (see, for example, Figs. 2, 3). In these recordings the net current was revealed, which reflected the combined contributions of both inward (calcium, sodium) and outward (potassium) currents. In the event that action potential generation was abnormal, examination of the net current provided a preliminary assessment of currents that might be affected. Currents were elicited by applying a series of depolarizing voltage commands $(-60$ to +90 in $10 \mathrm{mV}$ increments) from a holding potential of $-80 \mathrm{mV}$.

For the recording of isolated voltage-dependent sodium current $\left(I_{\mathrm{Na}}\right)$, potassium and calcium currents were suppressed by the use of the following solutions: the pipette solution contained (in $\mathrm{mM}$ ) $125 \mathrm{CsCl}, 10$ $\mathrm{NaCl}, 10$ EGTA, and 10 HEPES, pH 7.2 with $\mathrm{NaOH}$; the bath solution consisted of (in mM) $125 \mathrm{NaCl}, 20 \mathrm{TEA}-\mathrm{Cl}, 3 \mathrm{KCl}, 10 \mathrm{CoCl}_{2}$, and 10 HEPES, pH 7.2 with $\mathrm{NaOH}$. In a few experiments (e.g., Fig. $4 A$, top) $\mathrm{NaCl}$ was omitted from the pipette solution. Currents were elicited by applying a series of depolarizing $30 \mathrm{msec}$ voltage commands (from -60 to +90 in $10 \mathrm{mV}$ increments) from a holding potential of $-80 \mathrm{mV}$.

For the recording of isolated voltage-dependent potassium current $\left(I_{\mathrm{Kv}}\right)$, sodium and calcium currents were blocked as follows: the pipette solution contained (in mM) $135 \mathrm{KCl}, 10$ EGTA, and 10 HEPES, pH 7.2 with $\mathrm{KOH}$; the bath solution consisted of (in $\mathrm{mM}$ ) $145 \mathrm{NaCl}, 3 \mathrm{KCl}, 10$ $\mathrm{CoCl}_{2}$, and $10 \mathrm{HEPES}$ plus $1 \mu \mathrm{M}$ tetrodotoxin (TTX), pH 7.2 with $\mathrm{NaOH}$. Currents were elicited by applying a series of depolarizing 30 $\mathrm{msec}$ voltage commands (from -60 to +90 in $10 \mathrm{mV}$ increments) from a holding potential of $-80 \mathrm{mV}$.

Data analysis. The PULSE and IGOR programs (HEKA) were used to analyze data. Action potential duration was measured as the time required to regain half-amplitude of the impulse after the depolarizing current injection was stopped. Action potential overshoot is the maximum membrane voltage achieved during an action potential. Action potential amplitude is the difference between the overshoot and the holding potential. Peak $I_{\mathrm{Na}}$ refers to the absolute value of the maximum inward current that is elicited from a cell in response to a depolarizing series of voltage steps ranging between -60 and $+90 \mathrm{mV}$. The amplitude of $I_{\mathrm{Kv}}$ was measured as the average response 20-25 msec after the membrane potential was stepped to $+20 \mathrm{mV}$. Data are presented as mean \pm SEM. Levels of statistical significance were calculated with both an unpaired two-tailed Student's $t$ test and a nonparametric Mann-Whitney test, using the Statview Program (Abacus Concepts, Berkeley, CA).

Because it is not yet known whether the mutations present in the lines that were studied operate in a cell-autonomous manner, the studies reported here were performed on neurons in situ. Further, because zebrafish spinal neurons previously have not been studied electrophysiologically, it was critical first to determine their properties in vivo. Although the in situ preparation provides these key advantages, it also imposes restrictions on data analysis and interpretation. First, because the skin has been removed, it is not possible to examine aspects of the initial transduction event by applying tactile stimuli while recording from Rohon-Beard cells. Second, these neurons have processes of indeterminate but long length, and voltage errors arising from inadequate space clamp could be present; recordings that revealed inadequate space clamp (see above) were excluded from analysis. In addition, stable whole-cell configurations required that the electrodes be $\geq 4 \mathrm{M} \Omega$ in resistance, and this contributed to voltage errors arising from series resistance. Accordingly, for Figure $7 B$, analysis was limited to cells that had an estimated maximum voltage error caused by series resistance of $\leq 10 \mathrm{mV}$. However, 
the exclusion of cells with larger series resistance errors leads to an underestimate of current size; thus, for the analyses of Figures $4 B$ and 8 (peak $I_{\mathrm{Na}}$ ), such cells are included.

\section{RESULTS}

Motility or swimming of zebrafish embryos and larvae initiates either spontaneously or in response to specific sensory stimuli such as touch. The neural circuitry underlying swimming behavior has been studied in several species, and the majority of information is derived from studies in Xenopus (Roberts et al., 1981; Roberts and Clarke, 1982; Roberts, 1989; Fetcho, 1992; Arshavsky et al., 1993; Fetcho and O’Malley, 1995). Primary neurons, a collection of motor, sensory, and interneurons of early birth date, mediate swimming behavior. Interneurons and motor neurons form the central pattern generator that drives the alternating contractions of muscles on opposite sides required for efficient forward locomotion. Tactile stimuli excite mechanosensory Rohon-Beard cells (primary sensory neurons), which then activate the swimming central pattern generator.

Kimmel et al. (1995) charted key developmental behavioral landmarks of zebrafish embryos and larvae. With respect to early behavioral patterns, an initial transient behavior consisting of spontaneous rhythmic tail contractions is present between 22 and $27 \mathrm{hr}$ postfertilization (hpf). During this period the spontaneous contractions decrease in frequency and finally disappear. At the end of this period a response to touch is detected for the first time. Because the embryo cannot swim yet, the initial touch response consists of a single twitch of the tail away from the site of stimulation. At $48 \mathrm{hpf}$, when the embryo can swim, the response to tactile stimulation consists of a swimming episode.

Zebrafish motility mutants previously were isolated during a large-scale mutagenesis screen for genes with essential functions during embryonic development (Granato et al., 1996; Haffter et al., 1996a). During the large-scale screen the touch response was used primarily to elicit swimming behavior but also to assess touch sensitivity. Thus, this test was applied after swimming behavior was present (48 hpf; Kimmel et al., 1995; Granato et al., 1996). The simple touch response assay led to the isolation of a class of six complementing mutants (B5) that can swim spontaneously but not in response to touch (Granato et al., 1996). Given our interest in the role of activity during the earliest stages of nervous system development, alligator (ali), macho (mao), and steifftier (ste) were chosen for detailed study because their behavioral phenotypes were reported to appear as early as $48 \mathrm{hpf}$. In addition, a mutant isolated in a screen for pigmentation defects (Kelsh et al., 1996), touchdown (tdo), also was studied because homozygous mutant $t d o$ embryos have a reduced touch response at 48 hpf (Granato et al., 1996; Kelsh et al., 1996).

\section{Rohon-Beard neurons can be identified in situ}

A principal goal of this study was to determine whether defects in voltage-dependent ion channel function account for the behavioral phenotype of touch-insensitive mutants. Rohon-Beard primary sensory neurons mediate touch sensation. Rohon-Beard cell bodies reside within the spinal cord, whereas peripheral processes innervate the skin and respond to tactile stimuli via mechanosensitive terminals (Clarke et al., 1984; Spitzer, 1984).

Cell-cell interactions as well as growth factors that are prevalent during early stages of embryonic development are known to influence ion channel expression (Okamura et al., 1994; ToledoAral et al., 1995). Accordingly, the physiological study of RohonBeard neurons required an in situ preparation that preserves normal cell-cell interactions and exposure to growth factors. In

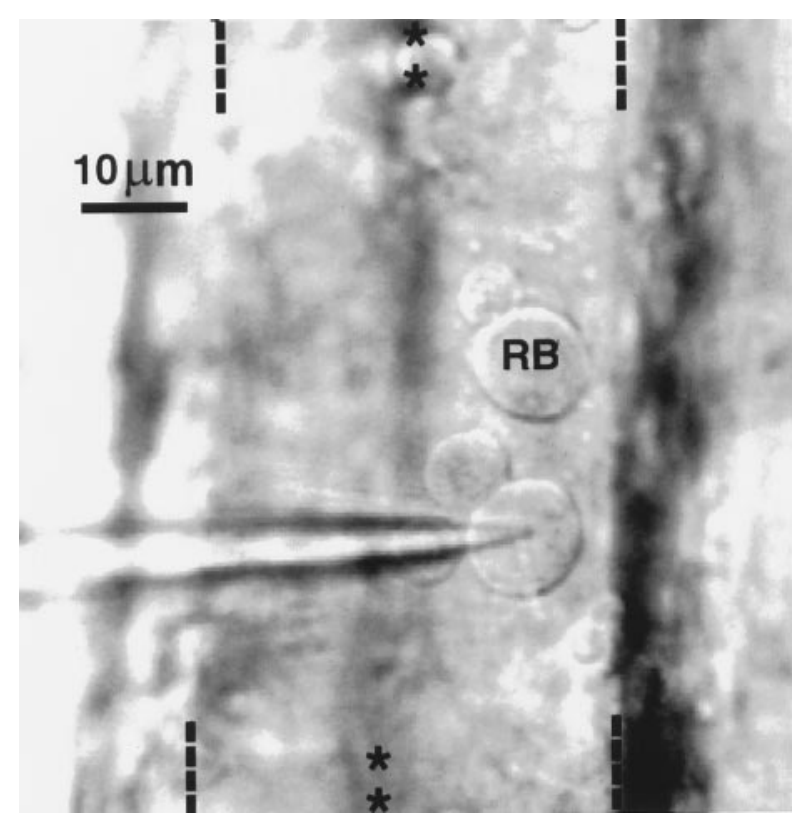

Figure 1. Rohon-Beard neurons are visualized with DIC/Nomarski optics in a dorsal view of a semi-intact preparation of a zebrafish embryo (36 hpf). Two Rohon-Beard neurons appear on the surface of the neural tube. One is under the tip of the electrode (arrow) and the other is labeled $R B$. They are identifiable via DIC optics on the basis of their dorsal position and large size (10 $\mu \mathrm{m}$ in diameter) in comparison to other spinal neurons (see also Grunwald et al., 1988). On removal of the meninges that ensheath the neural tube, many dorsal neurons separate from the rest of the neuroepithelium. This is the case for the two Rohon-Beard neurons as well as two smaller interneurons that appear in this photograph. The midline and lateral boundaries of the neural tube are indicated on the top and bottom of the photograph by rows of asterisks and dashes, respectively.

our semi-intact preparations (see Materials and Methods), Rohon-Beard cells are recognized on the basis of size and position by the use of DIC/Nomarski optics (Fig. 1). Studies of zebrafish neurons with antibody probes have indicated that Rohon-Beard cells have large cell bodies ( $\sim 10 \mu \mathrm{m}$; Bernhardt et al., 1990; Metcalfe et al., 1990) that distinguish them from neighboring dorsal neurons. Their large size previously has allowed for their reliable identification in live preparations, using DIC/Nomarski optics (Grunwald et al., 1988). These same morphological criteria also have enabled the successful identification of Rohon-Beard cells in semi-intact preparations of Xenopus embryos and larvae (Spitzer, 1976; Rohrbough and Spitzer, 1996).

Because the skin and meninges have been removed in the semi-intact preparations, zebrafish Rohon-Beard neuron cell bodies are accessible to patch-clamp electrodes, thus permitting electrophysiological investigation. Two physiological parameters further distinguish Rohon-Beard neurons from neighboring dorsal spinal neurons. First, Rohon-Beard cells have hyperpolarized resting membrane potentials (approximately $-70 \mathrm{mV}$, as shown in Table 1, for different mutant lines and sibling controls) in comparison to neighboring dorsal interneurons $(-50 \pm 1.7 \mathrm{mV}$; $n=23)$. The hyperpolarized value of the resting membrane potential of Rohon-Beard cells parallels that observed for Xenopus Rohon-Beard cells (Spitzer, 1976). Second, no spontaneous synaptic currents are observed, consistent with their sensory identity. In contrast, spontaneous synaptic currents are seen consistently in neighboring dorsal interneurons (data not shown). Thus, on the basis of morphological as well as physiological 
Table 1. Resting and excitable membrane properties of Rohon-Beard neurons of mao, ali, ste, and tdo homozygous mutant and unaffected sibling embryos (36-48 hpf)

\begin{tabular}{|c|c|c|c|c|c|}
\hline \multirow[b]{2}{*}{ Property examined } & \multicolumn{5}{|l|}{ Embryo type } \\
\hline & Control $(n)$ & $\operatorname{mao}(n)$ & $\operatorname{ali}(n)$ & ste $(n)$ & $t d o(n)$ \\
\hline Resting membrane potential (mV) & $-74 \pm 3(16)$ & $-72 \pm 4(8)$ & $-76 \pm 3(14)$ & $-72 \pm 3(16)$ & $-67 \pm 3(9)$ \\
\hline \multicolumn{6}{|c|}{ Action potential/active response characteristics: } \\
\hline Overshoot $(\mathrm{mV})$ & $16 \pm 3(10)$ & $-4.8 \pm 1.7(8)$ & $6.2 \pm 2.4(11)$ & $9.6 \pm 2.6(14)$ & $17 \pm 3(7)$ \\
\hline Amplitude (mV) & $102 \pm 3(10)$ & $75 \pm 3(8)$ & $89 \pm 2.6(11)$ & $92 \pm 3(14)$ & $105 \pm 3(7)$ \\
\hline Duration (msec) & $2.2 \pm 0.3(10)$ & $2.9 \pm 0.4(8)$ & $2.4 \pm 0.4(11)$ & $2.2 \pm 0.2(14)$ & $2.2 \pm 0.2(7)$ \\
\hline Cell membrane capacitance $(\mathrm{pF})$ & $3.5 \pm 0.1(65)$ & $3.4 \pm 0.1(92)$ & $3.3 \pm 0.2(20)$ & $3.6 \pm 0.12(37)$ & $2.9 \pm 0.24(8)$ \\
\hline
\end{tabular}

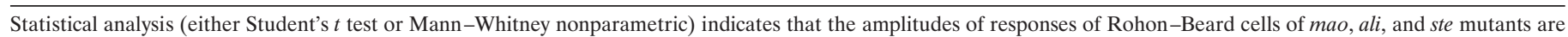

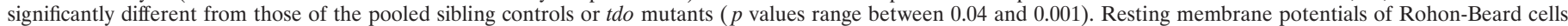

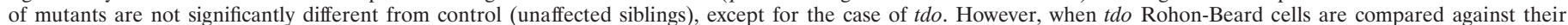

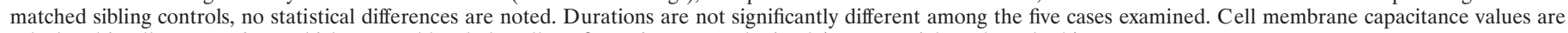
calculated in all neurons from which acceptable whole-cell configurations were obtained (see Materials and Methods).
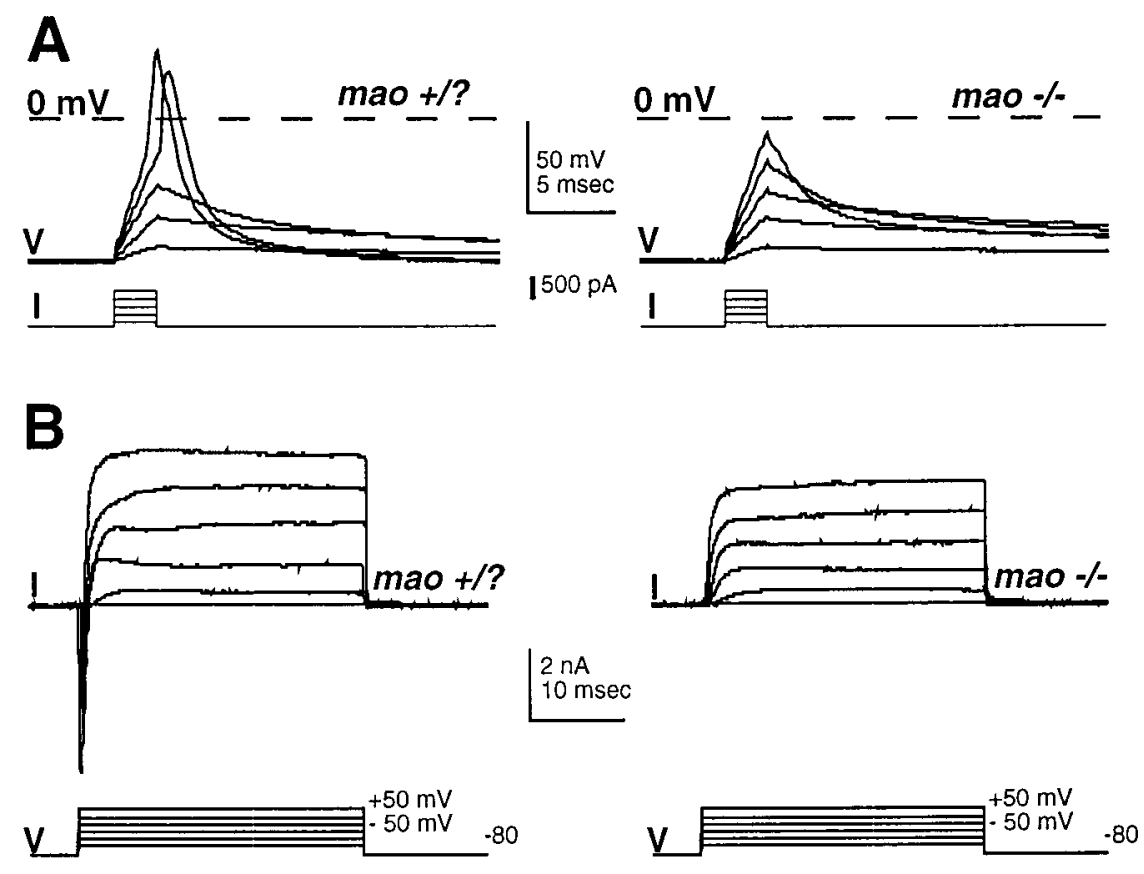

Figure 2. Rohon-Beard neurons of mao homozygous touch-insensitive zebrafish mutants fail to fire overshooting action potentials and lack a rapidly activating and inactivating inward current. Shown are action potentials $(A)$ and whole-cell voltagedependent currents $(B)$ recorded from neurons in control (48 hpf; left) and homozygous mao mutant (48 hpf; right) embryos. The control embryo is an unaffected sibling from the same clutch as the homozygous mutant. Whole-cell currents are recorded under the conditions used for action potential recording (see Materials and Methods), and thus the net current is revealed.

.

measures, Rohon-Beard cells constitute an identifiable population of primary spinal neurons that are amenable to electrophysiological study in semi-intact preparations of embryonic and larval zebrafish.

Rohon-Beard neurons of homozygous ali, mao, ste, and tdo mutants and their unaffected sibling embryos are identifiable in intact preparations by using the same morphological criteria that characterize Rohon-Beard neurons of wild-type embryos and larvae: relatively large cell bodies and dorsal position. In addition, electrophysiological properties that distinguish Rohon-Beard cells from neighboring neurons in wild-type embryos, such as a hyperpolarized resting membrane potential (Table 1) and the absence of spontaneous synaptic currents, also characterize these mechanosensory neurons in homozygous touch-insensitive mutant and unaffected sibling embryos.

\section{Rohon-Beard neuron action potential and whole-cell currents are affected in touch-insensitive mutants}

The original description of the behavior of ali, mao, ste, and tdo mutants refers to $48 \mathrm{hpf}$ embryos (Granato et al., 1996; Haffter et al., 1996a; Kelsh et al., 1996), which normally display a vigorous response to touch (Kimmel et al., 1995). mao homozygous mutant embryos display the strongest behavioral phenotype and, at 48 hpf, show no response to tactile stimulation. ali and ste homozygous mutant embryos show a reduced response to touch and can respond to strong tactile stimuli (Granato et al., 1996). tdo homozygous embryos initially (e.g., 1-3 dpf) lack touch sensitivity but later recover this phenotype (Granato et al., 1996; Kelsh et al., 1996).

Our studies began with analysis of mao mutants because their behavioral phenotype is strongest. The possibility that touch insensitivity is attributable to reduced cellular excitability was examined by using patch-clamp recording techniques in the whole-cell mode (Hamill et al., 1981). Action potentials fired by Rohon-Beard neurons of 48 hpf unaffected sibling embryos have pronounced overshoots (Fig. 2, Table 1). In contrast, RohonBeard neurons of mao homozygous embryos fail to fire overshooting responses. Nonspecific effects on membrane properties are unlikely to account for this result because resting membrane potentials, input resistances, and whole-cell capacitance values are not different between Rohon-Beard cells of homozygous 
Action Potentials
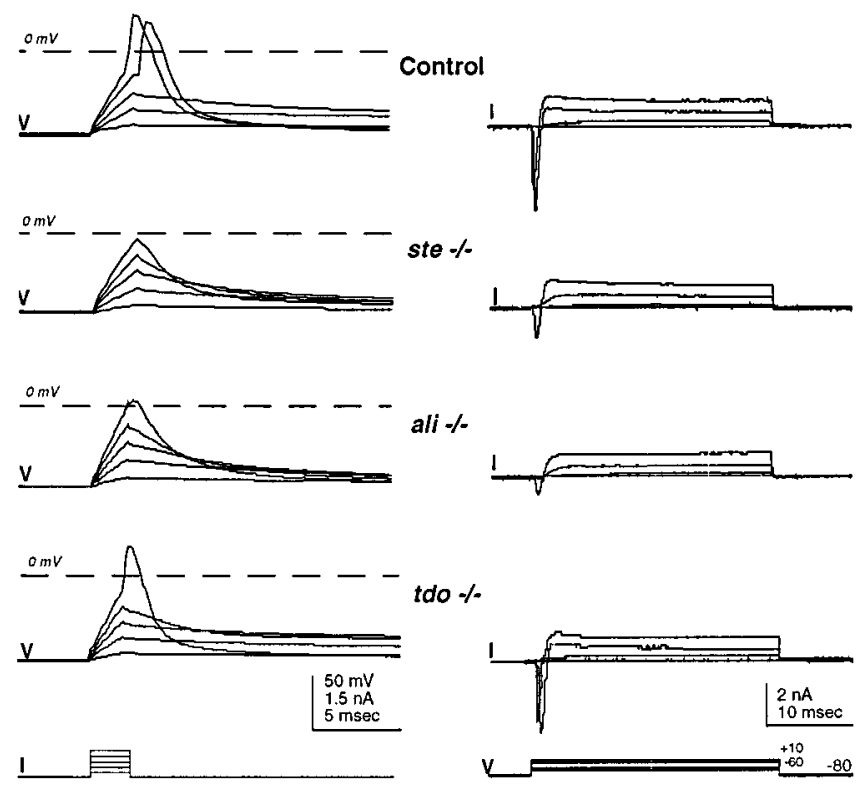

Figure 3. Rohon-Beard neurons of ali and ste homozygous touchinsensitive zebrafish mutants fire abnormal action potentials and have reduced rapid inward current. In contrast, neurons of $t d o$ mutants fire normal impulses. Shown are action potentials (left) and whole-cell voltage-dependent currents (right) recorded from unaffected ali sibling (Control; $48 \mathrm{hpf})$, homozygous ste (48 hpf), homozygous ali (48 hpf), and homozygous tdo (48 hpf) embryos. Whole-cell currents are recorded under the conditions used for action potential recording (see Materials and Methods), and thus the net current is revealed.

mutants and unaffected sibling embryos (Table 1; see Materials and Methods).

Elimination of the overshoot of the action potential suggests that the voltage-dependent sodium current is perturbed. Recording of whole-cell currents under conditions used for the recording of action potentials (see Materials and Methods) indicates that the amplitude of a rapidly activating and inactivating inward current is reduced in Rohon-Beard neurons of mao homozygous embryos. The initial inward current was often completely absent (Fig. 2), although outward currents were present. However, the kinetics and voltage dependence of the inward current that is affected by mutation of mao are consistent with its identity as a voltage-dependent sodium current. Because these recordings are performed under conditions for the recording of action potentials, the net current is revealed and thus large outward currents could mask inward currents. Thus, the isolation of sodium from other currents (see below) is required to assess more directly the effects of the mutations on the expression of sodium current.

Because embryos that are homozygous for mutations in the ali, ste, or tdo gene also show reduced sensitivity to touch at $48 \mathrm{hpf}$ (Granato et al., 1996; Kelsh et al., 1996), the electrical membrane properties of Rohon-Beard neurons in these mutants were characterized also (Fig. 3). In ali and ste homozygous embryos, Rohon-Beard cells often fail to fire overshooting responses. As for mao homozygous embryos, this defect does not appear to be attributable to nonspecific effects on membrane properties (Table 1; see Materials and Methods). In contrast, Rohon-Beard cells of tdo homozygous embryos show normal firing properties (Fig. 3).

The recording of total whole-cell currents indicates that a subset of Rohon-Beard neurons of ali and ste homozygous embryos exhibit a reduction in the amplitude of a rapidly activating and inactivating inward current (Fig. 3). In contrast, outward currents of normal amplitude are present. These results resemble those obtained from Rohon-Beard neurons of mao homozygous embryos. However, within single homozygous ali or ste mutant embryos, Rohon-Beard neurons fire action potentials with overshoots of variable amplitude. Although some overshoots are reduced severely (Fig. 3), others are within the normal range. This variability is evidenced by the more positive mean overshoot amplitude of action potentials fired by Rohon-Beard neurons of ali and ste mutants versus that of Rohon-Beard cells of mao mutants (Table 1).

mao mutants swim spontaneously but fail to do so in response to touch, suggesting that the defect is limited to sensory neurons. In wild-type embryos a range of action potential waveforms and sodium currents was recorded from the different classes of dorsal interneurons. In mao homozygous embryos, responses within the normal range were observed in interneurons (data not shown), consistent with a restriction of the deficit to sensory RohonBeard cells. Dorsal interneurons of ali, ste, and tdo homozygous embryos also were examined, and defects in action potential generation were not detected.

\section{Sodium current amplitude is reduced in touch-insensitive mutants}

The possibility that mutation of the mao, ali, or ste gene affects functional expression of sodium current was addressed directly by isolating sodium current $\left(I_{\mathrm{Na}}\right)$ by standard pharmacological and ion substitution methods (see Materials and Methods). Under these conditions all of the inward current recorded from RohonBeard neurons from wild-type or unaffected sibling embryos was blocked by $1 \mu \mathrm{M}$ TTX, a standard pharmacological blocker of the majority of neuronal voltage-dependent sodium channel isoforms. Further, the currents recorded under these conditions reversed between +60 and $+80 \mathrm{mV}$, as predicted by the Nernst equation for a sodium-dependent current $\left(E_{\mathrm{Na}}=+64 \mathrm{mV}\right)$. In addition, when sodium was omitted from the pipette solution, reversal was not observed over the same range of potentials, consistent with the predictions of the Nernst equation (Fig. $4 A$, top).

Whereas Rohon-Beard neurons of mao unaffected sibling embryos have a prominent $I_{\mathrm{Na}}$, it is reduced substantially in RohonBeard neurons of mao homozygous mutant embryos (Fig. $4 A$, top). However, $I_{\mathrm{Na}}$ is not eliminated completely; a small component persists that represents $\sim 10 \%$ of the total inward sodium current recorded from controls (Fig. 4B). This persistent component of $I_{\mathrm{Na}}$ also is blocked by $1 \mu \mathrm{M}$ TTX $(n=11)$.

The similarity of the effects of the mutation of ali or ste to the mutation of mao suggests that ali and ste also are required for the proper expression of sodium current. Similar to mao homozygous embryos, $I_{\mathrm{Na}}$ is reduced in Rohon-Beard neurons of ali and ste homozygous embryos (Fig. $4 A$, middle and bottom). However, an important difference distinguishes the effects of mutation of ste or ali from the mutation of mao. Within a single homozygous ali or ste mutant embryo, Rohon-Beard neurons have a broad range of peak $I_{\mathrm{Na}}$ amplitude values, with some approaching control values, whereas others are reduced nearly as severely as in mao homozygous embryos (Fig. 4B). This difference parallels the variability observed in the amplitude of action potential overshoots recorded from Rohon-Beard cells of ali and ste homozygous embryos.

Two other touch-insensitive mutants (Granato et al., 1996) 


\section{A Unaffected Sibling Controls}
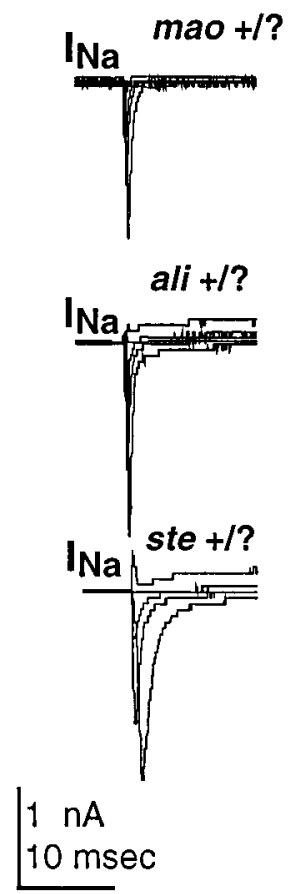

\section{Homozygous Mutants}
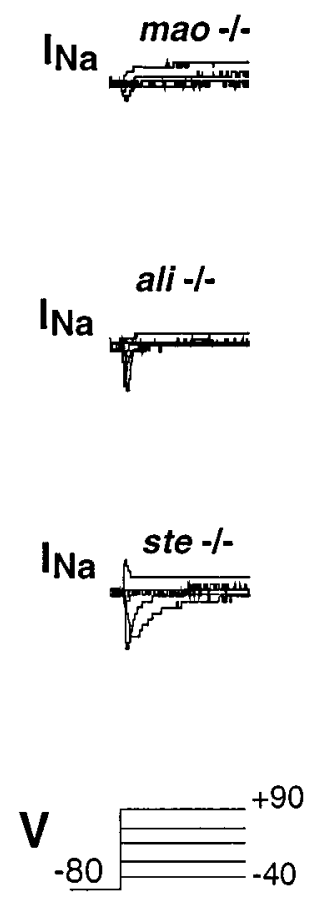

B

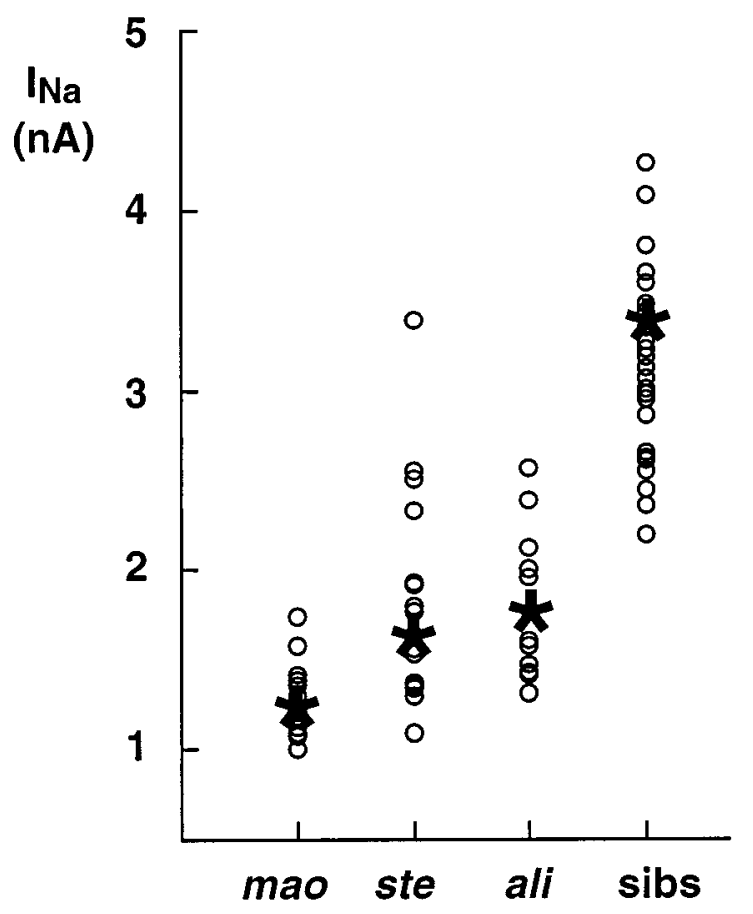

Figure 4. Whole-cell sodium current amplitude is reduced in Rohon-Beard cells of touch-insensitive mutants. $A$, Voltage-activated sodium currents were recorded from neurons in unaffected sibling embryos (48 hpf; left) and homozygous mao mutant (48 hpf; top right), homozygous ali mutant (48 hpf; middle right), and homozygous ste mutant ( $48 \mathrm{hpf} ;$ bottom right) embryos. The slower inactivation observed in the recordings from Rohon-Beard cells of ste homozygous mutant and unaffected siblings is a typical finding for ste mutants and the majority of sibling controls, of which $2 / 3$ are expected to be heterozygous. For the mao mutant and unaffected sibling exemplars that are shown (top), $\mathrm{NaCl}$ had not been added to the pipette solution (see Materials and Methods). B, Mutations in ali and ste lead to a variable and an overall smaller reduction of sodium current amplitude than does the mutation of $m a o$. The plot shows the distributions of peak sodium current amplitude recorded from neurons of mao, ali, and ste homozygous mutants and their unaffected siblings; the asterisks and circles designate the mean and individual values, respectively. Embryos ranged in age between 36 and 60 hpf.

were also examined: crocodile (cro), and schlaffi (sla). Their behavioral phenotype first appears relatively late $(3 \mathrm{dpf})$ versus the time of appearance of the mao, ali, ste, and tdo phenotypes (Granato et al., 1996). No defects in excitable membrane properties were detected in Rohon-Beard neurons of sla mutants. However, Rohon-Beard cells of cro mutants exhibited a $15 \%$ reduction in sodium current amplitude ( $n=4$; data not shown).

\section{mao function is required when embryos normally acquire touch sensitivity}

The results presented above suggest that, at $48 \mathrm{hpf}$, mutations that lead to a reduction in touch sensitivity of the embryo do so by reducing the functional expression of voltage-dependent $I_{\mathrm{Na}}$ and consequently preventing the generation or propagation of action potentials in mechanosensory Rohon-Beard cells. However, embryos first show a behavioral response to touch at an earlier time (Kimmel et al., 1995). We next determined when the behavioral phenotypes of ali, mao, and ste homozygous mutant embryos first appear and compared that with the time when wild-type embryos first display a behavioral response to tactile stimulation.

The first behavior displayed by zebrafish embryos is transient, present only between 22 and $27 \mathrm{hpf}$, and consists of spontaneous rhythmic tail contractions (Kimmel et al., 1995). In clutches produced by heterozygous mutant ali, mao, or ste carrier parents, none of the embryos is distinguishable from each other on the basis of these spontaneous contractions, indicating that this ear- liest behavior is not obviously affected. At $27 \mathrm{hpf}$, zebrafish embryos first show a consistent response to touch, consisting of the contraction of the tail away from the stimulated side of the embryo. This is the earliest time that embryos in a clutch produced by heterozygous mutant mao carriers are distinguishable from their unaffected siblings. Unaffected siblings respond to tactile stimulation, whereas the homozygous mao mutants fail to respond to a light touch of the trunk. Homozygous ali and ste mutant embryos are not identifiable until 5-6 hr later. The delayed appearance of the ali and ste phenotypes may reflect the variability in the cellular phenotype present in Rohon-Beard neurons (Figs. 3, 4) and consequent attenuation of the effect on the behavioral response to touch.

The behavior of wild-type and mutant embryos indicates that the consequences of the mutation of mao that lead to touch insensitivity are already present when embryos normally first display touch sensitivity ( $27 \mathrm{hpf}$ ). Accordingly, action potentials were recorded from Rohon-Beard cells of wild-type (wild-type Tü, 24-26 hpf) embryos just before the acquisition of touch sensitivity and compared with the action potentials of wild-type (wild-type Tü, 27-33 hpf) and mao homozygous (-/-) and unaffected sibling $(+/$ ?) embryos just after touch sensitivity normally is acquired (this is the earliest time that mao $-/-$ and $+/$ ? embryos can be identified). Just before the acquisition of touch sensitivity, Rohon-Beard neurons of wild-type embryos are ex- 


\section{Touch-Insensitive}

\section{Touch-Sensitive}
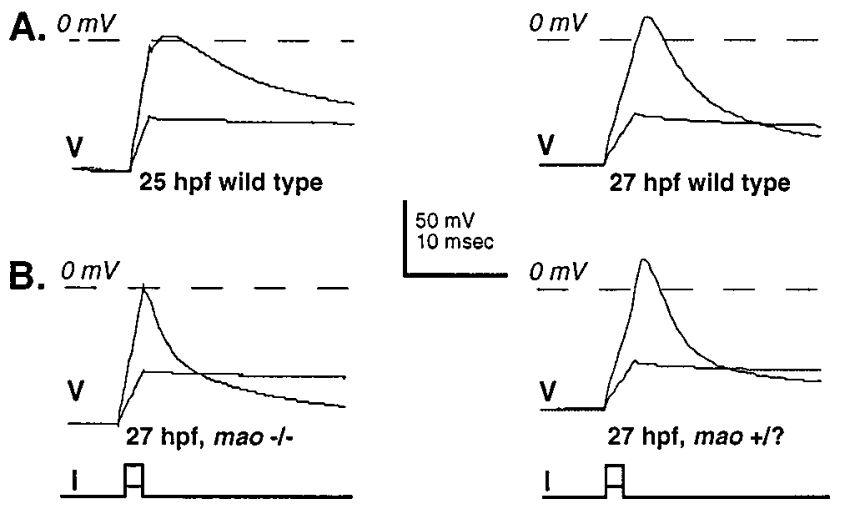

Figure 5. As touch sensitivity is being acquired, the amplitude of the overshoot of the action potential increases in Rohon-Beard neurons of wild-type, but not mao, homozygous embryos. $A$, Action potentials recorded from neurons in wild-type embryos before (25 hpf; left) and after (27 hpf; right) the acquisition of touch sensitivity. $B$, Action potentials recorded from neurons in unaffected sibling (right) and mao homozygous (left) 27 hpf embryos. mao $-/-$ and $+/$ ? embryos are not distinguishable before the time that touch sensitivity normally is acquired ( $27 \mathrm{hpf})$. At this time the action potentials are elicited from neurons of mao homozygous embryos. However, the amplitude of the overshoot of these action potentials is small and resembles that of action potentials of neurons of wild-type embryos before the acquisition of touch sensitivity (see also Table 2).

citable and fire action potentials in response to the injection of depolarizing current. However, these action potentials have small overshoots and prolonged durations (Fig. 5, top left, Table 2). In contrast, once the embryo responds to touch, Rohon-Beard neurons of wild-type embryos fire action potentials with prominent overshoots and reduced durations (Fig. 5, top right, Table 2).

At the time that a touch response is normally first present, Rohon-Beard neurons of mao homozygous embryos (27-33 hpf) fire action potentials with decreased overshoots but of normal duration (Fig. 5, bottom left, Table 2). This finding suggests that the developmental changes that lead to a decrease in the duration of the impulse occur normally, whereas those promoting an increase in the overshoot are disrupted by mutation of mao. These predictions are examined directly below.

\section{Developmental changes in sodium current are disrupted in Rohon-Beard neurons of mao homozygous embryos}

During the transition from a touch-insensitive to a touch-sensitive embryo, the action potential of Rohon-Beard cells undergoes a developmentally regulated shortening of its duration in addition to the increase in the amplitude of its overshoot. The change in duration of the action potential observed for zebrafish RohonBeard cells is reminiscent of the developmentally regulated changes in excitability reported previously for Xenopus RohonBeard cells (Baccaglini and Spitzer, 1977). In the case of amphibian spinal neurons the developmentally regulated change in impulse duration is attributable to an increase in functional expression of voltage-dependent potassium current, $I_{\mathrm{Kv}}$ (Barish, 1986; O’Dowd et al., 1988; Lockery and Spitzer, 1992). In Rohon-Beard cells of wild-type zebrafish embryos, $I_{\mathrm{Kv}}$ increases in amplitude during the transition to a touch-sensitive embryo (Fig. 6). mao homozygous mutant and unaffected sibling embryos are identifiable only after touch sensitivity is acquired (27 hpf) and thus cannot be studied before this time. At $27 \mathrm{hpf}$ the amplitude of $I_{\mathrm{Kv}}$ is not different in Rohon-Beard neurons of mao homozygous versus unaffected sibling embryos. Further, the amplitude of $I_{\mathrm{Kv}}$ in Rohon-Beard neurons of either mao homozygous or unaffected sibling embryos is not different from that found in Rohon-Beard neurons of wild-type embryos (Fig. 6).

An increase in sodium current is a likely explanation for the increasingly more positive values of the action potential overshoot. This possibility is supported by an examination of the amplitudes of the initial fast inward current that was recorded with the use of action potential recording conditions (data not shown). Moreover, direct examination of $I_{\mathrm{Na}}$ confirms that, in Rohon-Beard neurons of wild-type embryos, it increases in amplitude as touch sensitivity is acquired (Figs. $7 A, B, 8$ ). However, the peak $I_{\mathrm{Na}}$ of Rohon-Beard neurons of mao homozygous 27-33 hpf embryos is reduced substantially versus that of Rohon-Beard neurons of unaffected sibling and wild-type 28-33 hpf embryos. Mutation of mao prevents the developmentally regulated increase in peak $I_{\mathrm{Na}}$ and, consequently, of the overshoot of the action potential fired by Rohon-Beard cells. Thus, although changes in both $I_{\mathrm{Na}}$ and $I_{\mathrm{Kv}}$ of Rohon-Beard cells are noted during the transition from a touch-insensitive to a touch-sensitive embryo, the developmental changes in $I_{\mathrm{Kv}}$ occur normally, whereas those in $I_{\mathrm{Na}}$ are prevented in touch-insensitive mutants. These results implicate an essential role for a developmentally regulated $I_{\mathrm{Na}}$ in acquisition of a behavioral response to touch.

\section{DISCUSSION}

Physiological analyses of Rohon-Beard cells in touch-insensitive mutants reveal a reduction in functional expression of a voltagedependent sodium current and a consequent loss of cellular excitability. The reduction of sodium current and action potential generation or propagation prevents Rohon-Beard neurons from activating the swimming central pattern generator and thereby promoting a behavioral response. Although defects in RohonBeard mechanosensation or connectivity also could lead to a touch-insensitive phenotype, the reduction in cellular excitability suffices to account for the behavioral phenotype.

The mutations in mao, ali, and ste complement each other (Granato et al., 1996), suggesting that at least three different genes are required for the proper expression of $I_{\mathrm{Na}}$ in RohonBeard cells when a behavioral response to touch is first being acquired. During this same period, as well as later, Rohon-Beard neuron $I_{\mathrm{Na}}$ is increasing in amplitude. Similarly, throughout embryonic and larval development the behavioral response to touch appears to have an essential requirement for this current. None of the mutations leads to the complete elimination of voltagedependent $I_{\mathrm{Na}}$ (see Figs. 4, 7, 8). Similar to mammalian sensory neurons, Rohon-Beard cells most likely express more than one molecularly defined class of sodium channel. Although several scenarios could account for our results, the simplest one is that only one of the different classes of sodium channel that are normally present in Rohon-Beard cells is affected by the mutation of mao, ali, or ste, thus predicting a persistence of some $I_{\mathrm{Na}}$ in neurons from homozygous mutants. This model further predicts that mao, ali, or ste affects an $I_{\mathrm{Na}}$ that is regulated developmentally, and its functional expression normally increases during the transition from a touch-insensitive to touch-sensitive embryo.

Rohon-Beard neurons serve the function of peripheral dorsal root ganglion cells in the early zebrafish embryo and larva. The behavioral specificity of the touch-insensitive mutants suggests that the reduction of sodium current is limited to or is most 


\begin{tabular}{|c|c|c|c|c|}
\hline Property & $\begin{array}{l}\text { Wild-type Tü*, } \\
24-26 \text { hpf }(n)\end{array}$ & $\begin{array}{l}\text { Wild-type Tü*, } \\
27-33 \text { hpf }(n)\end{array}$ & $\begin{array}{l}\text { mao }-/- \\
27-33 \text { hpf }(n)\end{array}$ & $\begin{array}{l}\text { mao sibs, } \\
27-33 \mathrm{hpf}(n)\end{array}$ \\
\hline Resting membrane potential (mV) & $-66 \pm 2$ & $-63 \pm 2$ & $-66 \pm 2$ & $-58 \pm 0$ \\
\hline \multicolumn{5}{|l|}{ Action potential characteristics: } \\
\hline Overshoot (mV) & $7.7 \pm 3.0(11)$ & $16 \pm 1.1(15)$ & $-0.6 \pm 1.8(15)$ & $18 \pm 2.2(10)$ \\
\hline Amplitude (mV) & $95 \pm 2.8(11)$ & $102 \pm 2.0(15)$ & $85 \pm 2.0(15)$ & $102 \pm 1.6(10)$ \\
\hline Duration (msec) & $16 \pm 4.0(11)$ & $3.8 \pm 0.3(15)$ & $4.9 \pm 0.3(15)$ & $4.6 \pm 0.7(10)$ \\
\hline
\end{tabular}

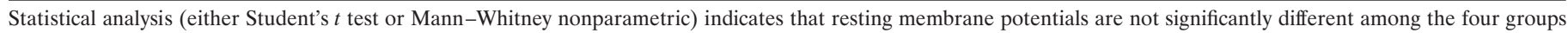

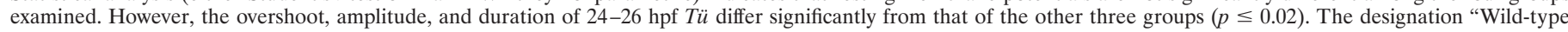

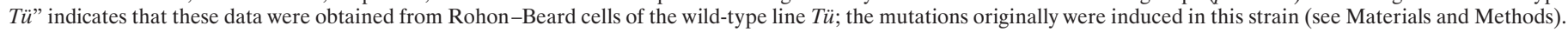

\section{A Touch-Insensitive Touch-Sensitive}
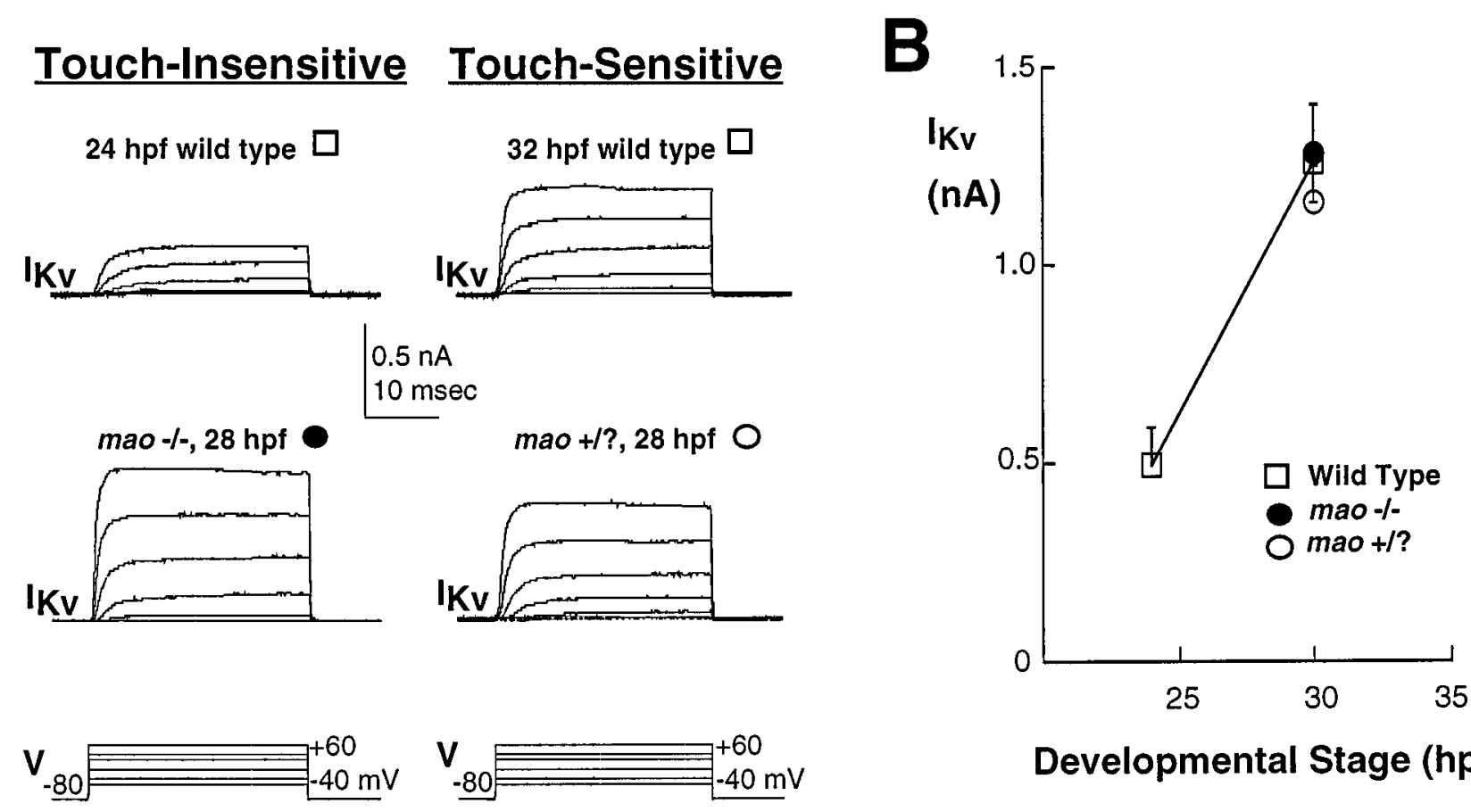

\section{Developmental Stage (hpf)}

Figure 6. Potassium current of Rohon-Beard cells increases in both wild-type and mutant embryos during the period of acquisition of touch sensitivity. $A$, Whole-cell potassium currents recorded in response to a series of depolarizing voltage steps. Data were obtained from neurons in a 25 hpf wild-type embryo that was not yet touch-sensitive (top left), a $27 \mathrm{hpf}$ wild-type embryo that did respond to touch (top right), a $28 \mathrm{hpf}$ mao homozygous embryo that did not respond to touch (bottom left), and a $28 \mathrm{hpf}$ unaffected sibling that was touch-sensitive (bottom right). mao $-/-$ and $+/$ ? embryos are not distinguishable before the time that touch sensitivity normally is acquired $(27 \mathrm{hpf}) . B$, The developmentally regulated increase in potassium current amplitude found at the time of the acquisition of touch sensitivity occurs in neurons of wild-type embryos (open squares), mao homozygous mutants ( filled circles), and their unaffected siblings (open circles). Potassium current amplitude $(+20 \mathrm{mV})$ is plotted as a function of the age of the embryo (hpf) in which the neurons were studied; the 25 and $30 \mathrm{hpf}$ points present data pooled for the 22-26 and $27-32 \mathrm{hpf}$ groups, respectively. In wild-type embryos the potassium current amplitude (open squares) increases substantially at the time of appearance of touch sensitivity. In mao homozygous mutants ( filled circles) the potassium current is of the same amplitude. The number of cells analyzed per point ranges between 4 and 13 .

pronounced in these mechanosensory neurons. Consistent with this prediction, excitability in dorsal interneurons was not affected in any obvious way. Are some vertebrate sodium channel isotypes expressed in a restricted pattern limited to sensory neurons? Indeed, some neuronal sodium channel types (e.g., PN1) appear to be expressed preferentially in sensory neurons of the peripheral nervous system rather than in central neurons (Toledo-Aral et al., 1997). Similarly, the sodium channel gene, SNS, which is thought to encode TTX-resistant sodium current, also is detected in most dorsal root ganglion neurons (Black et al., 1994). Other sodium channel genes also display cell-specific expression patterns; some are predominantly in muscle (Trimmer et al., 1989; Kallen et al., 1990), whereas different ones have their most robust or sole expression in the nervous system (Noda et al., 1986; Auld et al., 1988; Kayano et al., 1988; Schaller et al., 1992, 1995).
Neuronal sodium channels consist of pore-forming $\alpha$-subunits and auxiliary $\beta 1$ - and $\beta 2$-subunits (for review, see Marban et al., 1998). The genes that encode these subunits represent strong candidates for mao, ali, and ste. In both flies and mice the genes encoding either $\alpha$-subunits (Loughney et al., 1989; Burgess et al., 1995) or auxiliary subunits (Feng et al., 1995) of neuronal sodium channels have been identified by the study of mutants with specific behavioral phenotypes (e.g., temperature-sensitive paralysis). Similarly, mao, ali, and ste may encode structural components of sodium channels. However, the variable Rohon-Beard cellular phenotypes of the ali and ste mutants are difficult to reconcile with the mutation of a gene that encodes a structural element that is common to the affected sodium channel. Alternatively, mao, ali, and ste may be regulatory genes (e.g., transcription factors) required for the upregulation of $I_{\mathrm{Na}}$ during the transition from a 


\section{A Touch-Insensitive Touch-Sensitive}

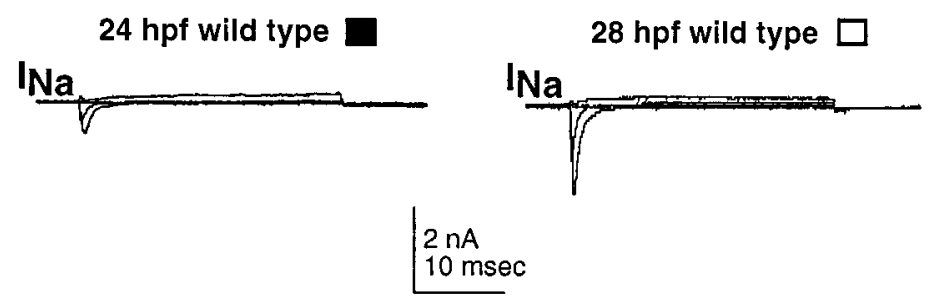

mao---, $33 \mathrm{hpf}$

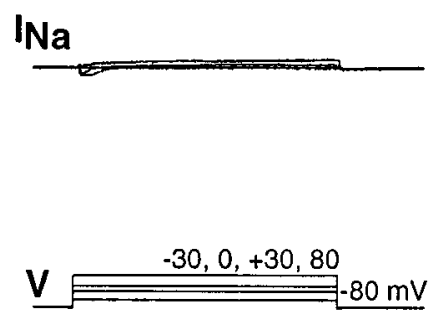

mao $+/ ?, 33$ hpf $O$
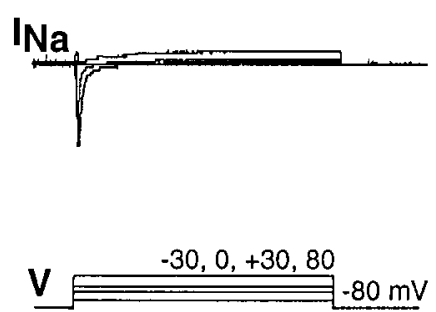

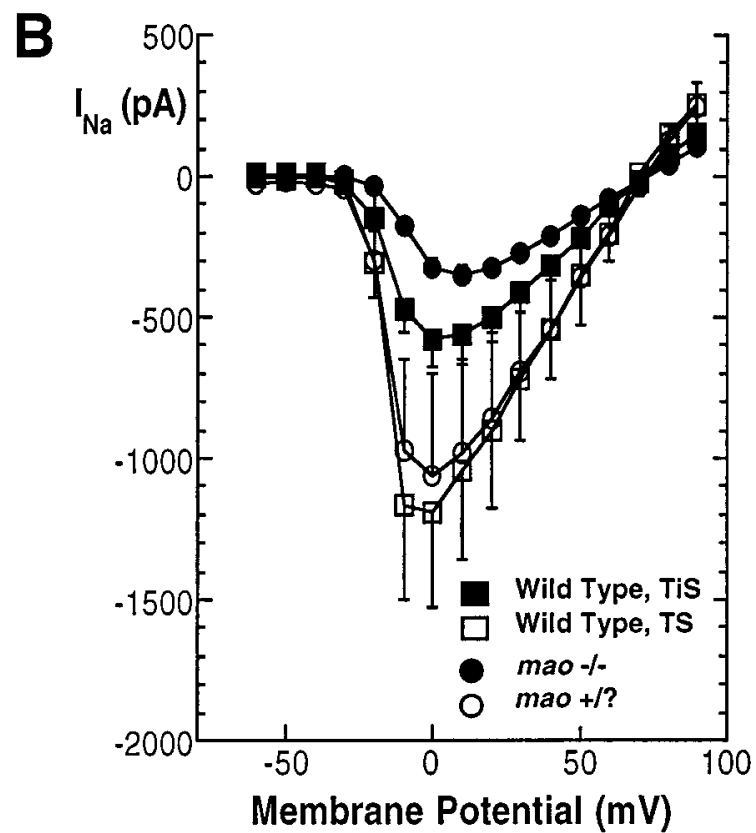

Figure 7. Sodium current of Rohon-Beard cells increases in wild-type, but not mutant, embryos during the period of acquisition of touch sensitivity. $A$, Whole-cell sodium currents recorded in response to a series of depolarizing voltage steps. Data were obtained from neurons in a 25 hpf wild-type embryo that was not yet touch-sensitive (top left), a $27 \mathrm{hpf}$ wild-type embryo that did respond to touch (top right), a 28 hpf mao homozygous embryo that did not respond to touch (bottom left), and an unaffected sibling that was touch-sensitive (bottom right). $B$, The current-voltage relationships for $I_{\mathrm{N}}$ recorded from Rohon-Beard neurons of touch-insensitive [either $24-26 \mathrm{hpf}$ wild-type $(n=10$; filled squares) or mao homozygous $(n=15 ;$ filled circles)] versus touch-sensitive [either $27-33 \mathrm{hpf}$ wild-type $(n=4$; open squares $)$ or mao unaffected siblings $(n=4$; open circles $)$ ] embryos are different in amplitude but otherwise appear similar. The cells that were analyzed for this figure were limited to those in which the voltage error caused by series resistance was estimated at $\leq 10 \mathrm{mV}$ (see Materials and Methods). TiS, Touch-insensitive; TS, touch-sensitive.

touch-insensitive to a touch-sensitive embryo. However, such a gene would need to act selectively in Rohon-Beard cells and affect specifically sodium, but not potassium, current functional expression or other excitable membrane properties. A gene encoding a DNA-binding protein that regulates sodium current expression has been identified by the cloning of Drosophila nap (Kernan et al., 1991). Further, in vertebrates, different signal transduction cascades and targeting mechanisms regulate either functional expression or subcellular localization of sodium current (D'Arcangelo et al., 1993; Toledo-Aral et al., 1997); thus, components of these pathways may be affected in the zebrafish mutants.

The zebrafish touch-insensitive mutants resemble human disease conditions, known as ion channelopathies, in that the expression of an ion channel is affected in a tissue-specific manner. The human ion channelopathies arise by the mutation of a single gene encoding an ion channel (Ackerman and Clapham, 1997). Similarly, the zebrafish mutants are likely to carry point mutations, because they were produced by an initial mutagenesis consisting of treatment with ethylnitrosourea, followed by outcrossing for at least five further generations (Haffter et al., 1996a). Because it is likely that a single gene is affected in each of the touch-insensitive mutants, the zebrafish mutants reveal one with an essential function during embryonic development. They as well as other zebrafish neurological mutants may serve as models for embryonic ion channelopathies that have been implicated in human developmental disorders such as epilepsy (Steinlein et al., 1995; Biervert et al., 1998) (for review, see Noebels, 1996).

The above considerations indicate that touch-insensitive mutants may harbor mutations in a sodium channel gene. Many sodium channel genes previously have been identified in other species, thus facilitating the identification of the mutated gene by using a candidate gene approach. However, a common goal of saturation screen mutagenesis is to reveal a previously unknown gene, and the mutation of an orthologue of a known gene is often considered less interesting. An important caveat exists for the case of embryonically expressed ion channel genes, because little is known regarding the role of specific ion channels or the mechanisms that provide stage- and cell-specific expression patterns. Further, genetic analyses of the earliest stages of nervous system development in mammals are often impractical because of the intrauterine development of the embryo. In contrast, zebrafish embryonic development occurs externally; thus, access to embryos at these early stages is straightforward. The mao mutant exemplifies these points.

The mao mutant also was isolated in a screen for fish with defects in their retinotectal projection (Baier et al., 1996; Granato et al., 1996; Trowe et al., 1996). In mao homozygous mutant embryos, retinal ganglion cell axons reach the tectum, indicating that pathfinding occurs normally. However, their mapping within the tectum is perturbed: the arbors of the retinal ganglion cells in the posterior ventral tectum, which contains the nasal-dorsal retinal projection, are enlarged; premature defasciculation is also evident. In many species this stage of connection formation is dependent on activity (Shatz and Stryker, 1988). Previous work (Stuermer et al., 1990) demonstrated that the application of TTX had no effect on the formation of the retinotectal projection in zebrafish. However, single axons were labeled at an age slightly younger than that of mutant larvae screened for retinotectal defects. On this basis the reexamination of the effects of activity and TTX on the formation of the retinotectal projection is war- 


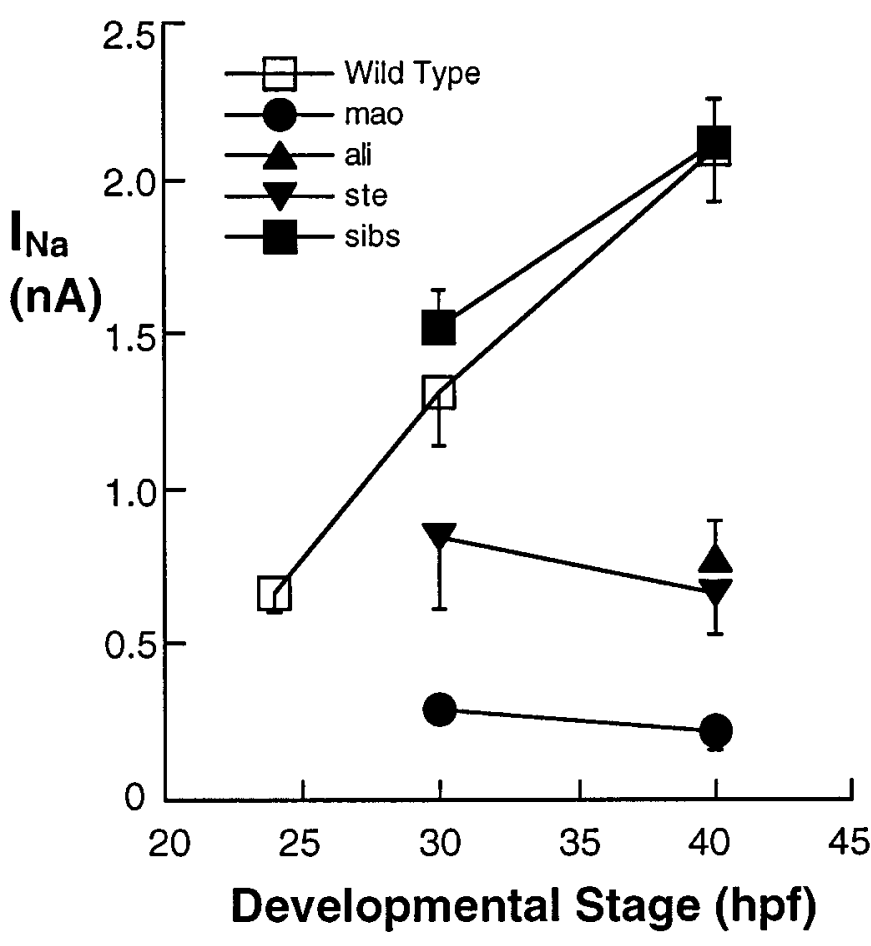

Figure 8. The large increase in sodium current amplitude found at the time of acquisition of touch sensitivity does not occur in neurons of touch-insensitive mutants. Peak sodium current amplitude is plotted as a function of the age (hpf) of the embryo in which the neurons were studied. The 25, 30, and $40 \mathrm{hpf}$ points present data pooled for the 22-26, 27-34, and 35-48 hpf groups, respectively; the number of cells analyzed per point ranged between 10 and 35 . In wild-type (open squares) and unaffected sibling ( filled squares) embryos the peak sodium current amplitude increased substantially at the time of appearance of touch sensitivity. In contrast, the normal increase in $I_{\mathrm{Na}}$ was prevented in ali (filled triangles) and ste (inverted filled triangles) homozygous embryos. Similarly, in neurons of mao homozygous mutants (filled circles), peak $I_{\mathrm{Na}}$ amplitude is even smaller than that found just before the acquisition of touch sensitivity in wild-type embryos. mao, ali, and ste $-/-$ and $+/$ ? embryos are not distinguishable until their behavioral phenotypes are present $(27,35$, and $33 \mathrm{hpf}$, respectively).

ranted. None of the other mutants studied here was isolated in the screen for mutants with defects in their retinotectal projection (Baier et al., 1996; Granato et al., 1996; Trowe et al., 1996). However, two other motility mutants-nevermind (nev) and whocares (woe) - do have abnormal retinotectal projections (Granato et al., 1996; Trowe et al., 1996) and, similar to mao, the defect is in mapping. These results indicate that even if mao (or nev or woe) encodes the orthologue of a previously identified sodium channel gene, such a mutant serves as a specific and sensitive probe of the role of activity in the formation of connections during embryonic development.

In sum, electrophysiological analysis indicates that functional expression of mechanosensory neuron sodium current is affected in three complementing touch-insensitive mutants. Genes encoding structural subunits of sodium channels as well as components of pathways that developmentally regulate or localize $I_{\mathrm{Na}}$ are good candidates for mao, ali, and ste. Study of zebrafish mutants thus will lead to the identification of embryonically expressed genes required for proper regulation of ion channels. Zebrafish ion channel mutants will serve as model systems for the examination of the role of activity of specific ion channels during the earliest stages of development of the vertebrate nervous system.

\section{REFERENCES}

Ackerman MJ, Clapham DE (1997) Ion channels-basic science and clinical disease. N Engl J Med 336:1575-1586.

Arshavsky YI, Orlovsky GN, Panchin YV, Roberts A, Soffe SR (1993) Neuronal control of swimming locomotion: analysis of the pteropod mollusc Clione and embryos of the amphibian Xenopus. Trends Neurosci $16: 227-233$

Auld VJ, Goldin AL, Krafte DS, Marshall J, Dunn JM, Catterall WA, Lester HA, Davidson N, Dunn RJ (1988) A rat brain $\mathrm{Na}^{+}$channel $\alpha$-subunit with novel gating properties. Neuron 1:449-461.

Baccaglini PI, Spitzer NC (1977) Developmental changes in the inward current of the action potential of Rohon-Beard neurones. J Physiol (Lond) 271:93-117.

Baier H, Klostermann S, Trowe T, Karlstrom RO, Nüsslein-Volhard C, Bonhoeffer F (1996) Genetic dissection of the retinotectal projection. Development 123:415-425.

Barish ME (1986) Differentiation of voltage-gated potassium current and modulation of excitability in cultured amphibian spinal neurons. J Physiol (Lond) 375:229-250.

Beckh S (1990) Differential expression of sodium channel mRNAs in rat peripheral nervous system and innervated tissues. FEBS Lett 262:317-322.

Beckh S, Noda M, Lubbert H, Numa S (1989) Differential regulation of three sodium channel messenger RNAs in the rat central nervous system during development. EMBO J 8:3611-3616.

Bernhardt RR, Chitnis AB, Lindamer L, Kuwada JY (1990) Identification of spinal neurons in the embryonic and larval zebrafish. J Comp Neurol 302:603-616.

Biervert C, Schroeder BC, Kubisch C, Berkovic SF, Propping P, Jentsch TJ, Steinlein OK (1998) A potassium channel mutation in neonatal human epilepsy. Science 279:403-405.

Black JA, Yokoyoma S, Higashida H, Ransom BR, Waxman SG (1994) Sodium channel mRNAs I, II, and III in the CNS: cell-specific expression. Brain Res Mol Brain Res 22:275-289.

Burgess DL, Kohrman DC, Galt J, Plummer NW, Hones JM, Spear B, Meisler MH (1995) Mutation of a new sodium channel gene Scn8a in the mouse mutant "motor endplate disease." Nat Genet 10:461-465.

Clarke JD, Hayes BP, Hunt SP, Roberts A (1984) Sensory physiology, anatomy, and immunohistochemistry of Rohon-Beard neurones in embryos of Xenopus laevis. J Physiol (Lond) 348:511-525.

D'Arcangelo G, Paradiso K, Shepherd D, Brehm P, Halegoua S, Mandel G (1993) Neuronal growth factor regulation of two different sodium channel types through distinct signal transduction pathways. J Cell Biol 122:915-921.

Drewe JA, Verma S, Frech G, Joho RH (1992) Distinct spatial and temporal expression patterns of $\mathrm{K}^{+}$channel mRNAs from different subfamilies. J Neurosci 12:538-548.

Driever W, Solnica-Krezel L, Schier AF, Neuhauss SCF, Malicki J, Stemple DL, Stainier DYR, Zwartkruis F, Abdelilah S, Rangini Z, Belak J, Boggs C (1996) A genetic screen for mutations affecting embryogenesis in zebrafish. Development 123:37-46.

Feng G, Deak P, Chopra M, Hall LM (1995) Cloning and functional analysis of TipE, a novel membrane protein that enhances Drosophila para sodium channel function. Cell 82:1001-1011.

Fetcho JR (1992) The spinal motor system in early vertebrates and some of its evolutionary changes. Brain Behav Evol 40:82-97.

Fetcho JR, O'Malley DM (1995) Visualization of active neural circuitry in the spinal cord of intact zebrafish. J Neurophysiol 73:399-406.

Granato M, van Eeden FJM, Schach U, Trowe T, Brand M, FurutaniSeiki M, Haffter P, Hammerschmidt M, Heisenberg C-P, Jiang Y-J, Kane DA, Kelsh RN, Mullins MC, Odenthal J, Nüsslein-Volhard C (1996) Genes controlling and mediating locomotion behavior of the zebrafish embryo and larva. Development 123:399-413.

Grunwald DJ, Kimmel CB, Westerfield M, Wlaker C, Streisinger G (1988) A neural degeneration mutation that spares primary neurons in the zebrafish. Dev Biol 126:115-128.

Haffter P, Granato M, Brand M, Mullins MC, Hammerschmidt M, Kane DA, Odenthal J, van Eeden FJM, Jiang Y-J, Heisenberg C-P, Kelsh RN, Furutani-Seiki M, Vogelsang E, Beuchle D, Schach U, Fabian C, Nüsslein-Volhard C (1996a) The identification of genes with unique and essential functions in the development of the zebrafish, Danio rerio. Development 123:1-36.

Haffter P, Odenthal J, Mullins MC, Lin S, Farrell MJ, Vogelsang E, Haas F, Brand M, van Eeden FJ, Furutani-Seiki M, Granato M, Hammerschmidt M, Heisenberg C-P, Jiang Y-J, Kane DA, Kelsh RN, Hopkins 
N, Nüsslein-Volhard C (1996b) Mutations affecting pigmentation and shape of the adult zebrafish. Dev Genes Evol 206:260-276.

Hamill OP, Marty A, Neher E, Sakmann B, Sigworth FJ (1981) Improved patch-clamp techniques for high resolution current recording from cells and cell-free membrane patches. Pflügers Arch 391:85-100.

Kallen RG, Sheng ZH, Yang J, Chen L, Rogart RB, Barchi RL (1990) Primary structure and expression of a sodium channel characteristic of denervated and immature rat skeletal muscle. Neuron 4:233-242.

Katz LC, Shatz CJ (1996) Synaptic activity and the construction of cortical circuits. Science 274:1133-1138.

Kayano T, Noda M, Flocker V, Takahashi H, Numa S (1988) Primary structure of rat brain sodium channel III deduced from the cDNA sequence. FEBS Lett 228:187-194.

Kelsh RN, Brand M, Jiang Y-J, Heisenberg C-P, Lin S, Haffter P, Odenthal J, Mullins MC, van Eeden FJM, Furutani-Seiki M, Granato M, Hammerschmidt M, Kane DA, Warga RM, Beuchle D, Vogelsang L, Nüsslein-Volhard C (1996) Zebrafish pigmentation mutations and the processes of neural crest development. Development 123:369-389.

Kernan MJ, Kuroda MI, Kreber R, Baker BS, Ganetzky B (1991) nap ts, a mutation affecting sodium channel activity in Drosophila, is an allele of mle, a regulator of X chromosome transcription. Cell 66:949-959.

Kimmel CB, Ballard WW, Kimmel SR, Ullmann B, Schilling TF (1995) Stages of embryonic development of the zebrafish. Dev Dyn 203:253-310.

Lockery SR, Spitzer NC (1992) Reconstruction of action potential development from whole-cell currents of differentiating spinal neurons. J Neurosci 12:2268-2287.

Loughney K, Kreber R, Ganetzky B (1989) Temperature-sensitive paralytic mutations on the second and third chromosomes of Drosophila melanogaster. Genet Res 40:191-199.

Marban E, Yamagishi T, Tomaselli GF (1998) Structure and function of voltage-gated ion channels. J Physiol (Lond) 508:647-657.

Metcalfe WK, Myers PZ, Trevarrow B, Bass MB, Kimmel CB (1990) Primary neurons that express L2/HNK-1 carbohydrate during development in the zebrafish. Development 110:491-504.

Mullins MC, Hammerschmidt M, Haffter P, Nüsslein-Volhard C (1994) Large-scale mutagenesis in the zebrafish: in search of genes controlling development in a vertebrate. Curr Biol 4:189-202.

Noda M, Ikeda T, Suzuki H, Takeshima H, Takahashi T, Kuno M, Numa S (1986) Expression of functional sodium channel messenger RNAs in rat brain. Nature 320:188-192.

Noebels JL (1996) Targeting epilepsy genes. Neuron 16:241-244.

Nüsslein-Volhard C, Weischaus E (1980) Mutations affecting segment number and polarity in Drosophila. Nature 287:795-801.

O’Dowd DK, Ribera AB, Spitzer NC (1988) Development of voltagedependent calcium, sodium, and potassium currents in Xenopus spinal neurons. J Neurosci 8:792-805.

Okamura Y, Ono F, Okagaki R, Chong JA, Mandel G (1994) Neural expression of a sodium channel gene requires cell-specific interactions. Neuron 13:937-948.

Rauch G-J, Granato M, Haffter P (1997) A polymorphic line for genetic mapping using SSLPs on high-percentage agarose gels. Tech Tips Online T01:208.

Roberts A (1989) The neurons that control axial movements in a frog embryo. Am Zool 29:178-186.
Roberts A, Clarke JDW (1982) The neuroanatomy of an amphibian spinal cord. Philos Trans R Soc Lond [Biol] 296:195-212.

Roberts A, Kahn JA, Soffe SR, Clarke JDW (1981) Neural control of swimming in a vertebrate. Science 213:1032-1034.

Rohrbough J, Spitzer NC (1996) Regulation of intracellular $\mathrm{Cl}^{-}$levels by $\mathrm{Na}\left({ }^{+}\right)$-dependent $\mathrm{Cl}^{-}$cotransport distinguishes depolarizing from hyperpolarizing $\mathrm{GABA}_{\mathrm{A}}$ receptor-mediated responses in spinal neurons. J Neurosci 16:82-91.

Schaller KL, Krzemien DM, McKenna NM, Caldwell JH (1992) Alternatively spliced sodium channel transcripts in brain and muscle. J Neurosci 12:1371-1381.

Schaller KL, Krzemien DM, Yarowsky PJ, Krueger BK, Caldwell JH (1995) A novel, abundant sodium channel expressed in neurons and glia. J Neurosci 15:3231-3242.

Shatz CJ (1994) Role for spontaneous neural activity in the patterning of connections between retina and LGN during visual system development. Int J Dev Neurosci 12:531-546.

Shatz CJ, Stryker MP (1988) Prenatal tetrodotoxin infusion blocks segregation of retinogeniculate. Science 242:87-89.

Solnica-Krezel L, Schier AF, Driever W (1994) Efficient recovery of ENU-induced mutations from the zebrafish germline. Genetics 136:1401-1420.

Spitzer NC (1976) The ionic basis of the resting potential and a slow depolarizing response in Rohon-Beard neurones of Xenopus tadpoles. J Physiol (Lond) 255:105-135.

Spitzer NC (1984) What do Rohon-Beard cells do? Trends Neurosci 7:224-225.

Spitzer NC (1991) A developmental handshake: neuronal control of ionic currents and their control of neuronal differentiation. J Neurobiol 22:659-673.

Steinlein OK, Mulley JC, Propping P, Wallace RH, Phillips HA, Sutherland GR, Scheffer IE, Berkovic SF (1995) A missense mutation in the neuronal nicotinic acetylcholine receptor $\alpha 4$ subunit is associated with autosomal dominant nocturnal lobe epilepsy. Nat Genet 11:201-203.

Stuermer CA, Rohrer B, Munz H (1990) Development of the retinotectal projection in zebrafish embryos under TTX-induced neural-impulse blockade. J Neurosci 10:3615-3626.

Toledo-Aral JJ, Brehm P, Halegoua S, Mandel G (1995) A single pulse of nerve growth factor triggers long-term neuronal excitability through sodium channel induction. Neuron 14:607-611.

Toledo-Aral JJ, Moss BL, He Z-J, Koszowski AG, Whisenand T, Levinson SR, Wolf JJ, Silos-Santiago I, Halegoua S, Mandel G (1997) Identification of PN1, a predominant voltage- dependent sodium channel expressed principally in peripheral neurons. Proc Natl Acad Sci USA 94:1527-1532.

Trimmer JS, Cooperman SS, Tomiko SA, Zhou J, Crean SM, Boyle MB, Kallen RG, Sheng Z, Barchi RL, Sigworth FJ, Goodman RH, Agnew WS, Mandel G (1989) Primary structure and functional expression of a mammalian skeletal muscle sodium channel. Neuron 3:33-49.

Trowe T, Klostermann S, Baier H, Granato M, Crawford AD, Grunewald B, Hoffmann H, Karlstrom RO, Meyer SU, Muller B, Richter S, Nüsslein-Volhard C, Bonhoeffer F (1996) Mutations disrupting the ordering and topographic mapping of axons in the retinotectal projection of the zebrafish, Danio rerio. Development 123:439-450. 